\title{
Open Educational Resources and the Transformation of Education
}

\author{
Ilkka Tuomi \\ 3 December 2012 \\ to appear in \\ European Journal of Education 48(1), 2013
}

Abstract

The extremely rapid expansion of open educational resource (OER) initiatives and the millions of learners they attract can be understood as an indicator of an emerging revolution in education and learning. This paper describes recent developments in this area and develops conceptual foundations for studies and policies on OER. We describe four different types of OER, locate these in a field of learning theories, and discuss how the wide adoption of OER may constrain and accelerate the transformation of learning and education in the knowledge society. 


\section{Open educational resources and the transformation of education}

\section{Introduction}

Evolution becomes revolution when the established institutional order changes and new social practices and concepts start to organize everyday activity and discourse. The Open Educational Resources (OER) movement potentially represents such a revolution. Stanford's machine learning and artificial intelligence courses enrolled over 260,000 students from more than 190 countries in Fall 2011, spinning-off the two venture capital funded start-ups Coursera and Udacity. The MIT and Harvard University press conference on the edX OER initiative gained over 35,000 viewers on YouTube after its launch in May 2012. The introductory video for Stanford's "Designing a New Learning Environment" course, which run from October 15, 2012 to December 20, 2012, had over 15000 viewers in the first weeks of the course. In October 2012, on the first day of the Peer 2 Peer University's massive instructor-less open online course (MOOC) on Python programming language, there were 5,814 registrants for the course. ${ }^{1}$

The numbers are impressive. One teacher, 50000 students. No teacher, 6000 learners. Combined with the analytical capabilities of state-of-the-art ICT, this creates new possibilities. In the prototype MIT edX course, "Circuits \& Electronics," there was a student who received 100 percent on all of the assignments He was a 15-year-old boy from Nepal. ${ }^{2}$

Just like in the other recent hyper-fast developments on the net, there is nothing very new in OER from an ICT point of view. The rapid expansion of social media applications occurs because there are few technical obstacles to overcome. As Internet infrastructures have matured to a point where massive numbers of users can be supported at extremely low costs, the speed of technology diffusion is now limited by the users.

This new dynamic of change is certainly extraordinary, if not revolutionary, and many educational institutions have realized this. Coursera, which provides a platform for universities to roll-out their OER courses, grew from its four founding partner universities to 33 in its first five months in 2012. The OpenCourseWare consortium had almost two hundred higher education institutions as its members towards the end of 2012, including the China Open Resources for Education (CORE) consortium, with 35 member universities. The Khan Academy now provides over 3,400 courses and is used by some 3.5 million students each month. The open source learning management platform Moodle has now over 60 million registered users.

Although open educational resources, strictly speaking, do not have to be digital and network accessible, in practice the rapidly declining costs of ICT and the explosive growth of the Internet have been major forces driving the expansion of OER. Internet-based resources have been used in education at least since the late 1980s, but their use has grown rapidly after Gopher and the World Wide Web provided access to digital documents and multimedia. Since the birth of the Web in 1990, open access to scholarly publications has expanded fast (Suber 2012). Towards the end of the millennium there were over 500 peer-reviewed open access journals (Laakso et al. 2011); by October 2012, over 8,000 journals had been added to the the Directory of Open Access Journals

1 The data in this paragraph comes from the respective web sites.

2 Rodrik, D., and K. Sun. EdX: Harvard's New Domain. The Harvard Crimson. http://www.thecrimson.com/article/2012/10/4/edx-scrutiny-online-learning/. 
hosted by the Lund University ${ }^{3}$. There are now over 2900 institutional and cross-institutional open access repositories registered in the Registry of Open Access Repositories (ROAR), hosted at the University of Southampton. ${ }^{4}$

The growth of Open Access has been facilitated by copyright practices that emerged in the free software community in the1980s. The idea of using copyright to enable access, reuse and further development of digital assets was rapidly taken up in the educational context by David Wiley, who coined the term Open Content in 1998 (Grossman 1998), and the idea was more formally developed by the Creative Commons initiative, launched by Lawrence Lessig and his collaborators in 2002 (Plotkin 2002).

Open source software projects such as the Linux operating system and the Apache http server have also provided a major impetus for OER. Towards the end of 1990's, the open source movement clearly highlighted the potential of peer-produced resources (Oram 2001; Raymond 1999; Weber 2004), as well as the potential of the collaborative open source development model for knowledge creation and learning (Tuomi 2002). Many software platforms for learning have been developed as open source projects, including OLAT (1999, University of Zürich), Claroline (started in 2000 at the Catholic University of Louvain), as well as Moodle (first released in 2002 by Martin Dougiamas at Curtin University, Australia), which now has over 68,000 active registered sites in 222 countries. $^{5}$ The open source software development model was also the starting point for Connexions, launched at the Rice University in1999 by Richard Baraniuk. Connexions was designed for creating and sharing peer-produced learning resources, as a platform where modular learning objects could be stored, refined, and remixed. It has now more than 17,000 learning objects or modules in its repository, used by over 2 million people per month. ${ }^{6}$

Open Educational Resources is now viewed as a natural way to implement distance learning, open education and new pedagogical approaches (e.g. OECD 2007; Thomas and Brown 2011; Okada, Connolly, and Scott 2012; Ehlers 2011). As an indication of a widely shared belief that OER is going to be a fundamentally important phenomenon for the future of learning and education, the UNESCO World OER Congress in June 2012 released the Paris OER Declaration (UNESCO 2012), which requests the member states to foster and facilitate the use and development of OER. OER is also one of the priorities proposed by the European Commission in its communication on Rethinking Education (EC 2012), published in November 2012.

There are very many OER initiatives around the world, and policymakers are actively developing policies in this area (Hylén et al. 2012). The developers and participants of OER initiatives often describe OER as a "movement." As the phenomenon is recent and rapidly evolving, literature on OER remains highly descriptive, prescriptive, and often speculative. To gain better understanding on the developments in this area, Carnegie Mellon and the UK Open University set up the Evidence Hub for Open Education as a part of their OLnet project, in an attempt to bring researchers and educators together to share knowledge on OER. ${ }^{7}$ More recently, the UNESCO supported OER community mailing list was re-launched in November 2012 in an attempt to create a world map of OER activities. In the EU, the POERUP (Policies for OER Uptake) project, funded by the EU Lifelong Learning Programme in 2011-2014, is also conducting a large number of case studies with an objective to develop recommendations for governments that want to stimulate OER.

\footnotetext{
3 http://www.doaj.org

4 http://roar.eprints.org

5 http://moodle.org/stats, October 2012.

6 http://cnx.org/aboutus/, October 2012.

7 http://www.olnet.org/
} 
In this paper, we focus on developing theoretical and conceptual understanding of this potentially important phenomenon. Instead of trying to capture a moving target, the paper tries to put OER in a broader context of educational transformation.

Openness is, of course, an extremely complex issue that has social, economic, cognitive and technical dimensions. OER also requires that the institutions of education reconsider their mandates and roles (McAndrew 2010; Gourley and Lane 2009; Butcher 2011; Schaffert 2010). Many debates and several recent policy initiatives on open educational resources have focused on no-cost access to teaching and learning materials ${ }^{8}$ and the economic viability of OER models (e.g., de Langen 2011). In practice, there are many stakeholders, and what is no-cost for someone is not necessarily free for all. Similarly, openness cannot simply be reduced to access. To understand the potential impact of OER, we have to provide a more detailed picture about the conditions of openness, as well as the nature of open resources.

The paper is organized as follows. The next section defines four different key types of OER that will be distinguished in the discussions throughout the paper. Openness and freedom exist in a social context that includes, for example, intellectual property rights, but also many other social institutions. The following section therefore puts OER in a context of social institutions and production and prosumption processes. To provide critical background for analyzing the potential impact of OER in the transition from the industrial age towards the knowledge society, the paper then revisits four key societal functions of education and contrasts the ways in which these are implemented in the industrial and knowledge societies. The following section then puts the key technical characteristics of the different types of OER in resonance with alternative models of learning, consolidating these into two dimensions, one focused on the individualistic-distributed axis, and another on a repository-process axis. Using the conceptual outcomes of the previous sections, the paper then outlines some examples of how OER could shape the transformation of education and learning. The final section summarizes the paper.

\section{The four types or OER}

Open Educational Resources gained visibility in 2002, when UNESCO organized the Forum on the Impact of Open Courseware for Higher Education in Developing Countries. The forum was partly inspired by the recently published OpenCourseWare Initiative of the MIT and existing initiatives such as the MERLOT (Multimedia Educational Resource for Learning and Online Teaching) launched in 1997 in the US.

The UNESCO forum defined Open Educational Resources as "the open provision of educational resources, enabled by information and communication technologies, for consultation, use and adaptation by a community of users for non-commercial purposes." (UNESCO 2002, 24). Later, the restriction to non-commercial purposes was removed, and more recently the definition has been expanded to include also non-digital materials (UNESCO 2012). A frequently used definition of OER is the one provided by one of the key funders of OER initiatives around the world, the William and Flora Hewlett Foundation (Atkins, Brown, and Hammond 2007, 4):

8 For example, in October 2012 California decided to create a web site that will give students free digital access to 50 core textbooks (http://www.20mm.org). As a part of its Digital School program, Poland adopted in April 2012 regulation that will create free textbooks for grades 4-6 in primary schools (http://nowoczesnapolska.org.pl/2012/04/03/free-textbooks-are-part-of-digital-school-programme). In July 2012, the Finch report recommended that UK adopts a clear policy direction towards open access. The Guardian called this "the most radical shakeup of academic publishing since the invention of the Internet" (Sample 2012). 
"OER are teaching, learning, and research resources that reside in the public domain or have been released under an intellectual property license that permits their free use or repurposing by others. Open educational resources include full courses, course materials, modules, textbooks, streaming videos, tests, software, and any other tools, materials, or techniques used to support access to knowledge."

These definitions are intuitive, but they can be made more accurate by defining what we mean by resources.

According to a dictionary definition, a resource is "a stock or supply of materials or assets that can be drawn in order to function effectively" (OECD 2007, chap. 2). ${ }^{9}$ Economists distinguish "rival" and "non-rival" and "excludable" and "non-excludable" resources. Resources that are rival and non-excludable are often called "common pool resources." Typical examples include ocean fisheries. It is difficult to restrict access to open seas, but when someone fishes the pool the size of the fish pool available for others diminishes. Unrestricted and unregulated use of common pool resources is usually thought to lead to the infamous "tragedy of commons" (Hardin 1968), where the resource is eventually overused, depleted, and destroyed.

Resources, however, can also be "non-rival." A specific characteristic of a non-rival resource is that it can be enjoyed without diminishing the enjoyment of others. When resources are non-rival and access to them is not restricted they are "public goods." Knowledge, education, and public parks are often given as examples of public goods (Hess and Ostrom 2003). ${ }^{10}$ Open educational resources can therefore be described as public goods, and large bodies of economic literature become relevant in explaining why and when policy intervention is justified for such goods.

OER is, however, something more than a public good. When OER is produced in a collaborative fashion where the use and remixing of the content increases the value of the resource, one core assumption of economic theory, the separation between consumption and production breaks down. The consumption of OER can expand the resource. Open source software and OER, therefore, have also been described as "open fountains of goods" (Tuomi 2005). In an open fountain model, the more the pool is used, the bigger it gets. ${ }^{11}$ This leads to new models of value creation that cannot easily be analyzed using current economic theory or economic policy analysis tools.

Keeping in mind that also new theoretical frameworks may be needed, open educational resources can be defined as accumulated assets that are available in a non-discriminatory way to educators, students and self-learners for learning and education. When they can be enjoyed without reducing the possibilities of others to enjoy them, they are public goods. When the users can re-develop and contribute to the resource, open resources can also provide "fountains of goods."

9 The OECD definition is based on an unpublished background report by Tuomi (2006). The present section draws on this background report.

10 Whether education really provides an example of a public good is, however, a rather complicated issue. Education can also be viewed as a defensive cost that people have to spend to avoid falling behind others in job-market queues (Thurow 1975). For this reason, expenditure on education is partially counted as investment and partially as cost in some indicators of sustainable economic growth (e.g., Daly and Cobb 1989).

11 OER can also be described as "private production of public goods" (O’Mahony 2003; von Hippel and von Krogh 2003), and "commons-based peer production" (Benkler 2006). Historically, the "increasing returns" to scale of production is, of course, a complex and contested issue (e.g. Buchanan and Yoon 1994). 
This definition is somewhat less intuitive and also broader than, for example, the current UNESCO definition. It highlights, however, theoretically and practically important distinctions. To make these clear, we separate four different types of OER.

The first level of openness is about access and accessibility. A practical criterion for such openness is whether there is a non-discriminatory opportunity to reach, explore, and study the resource. We call OER that is open in this sense OER I. No-cost access to textbooks is an example of OER I. ${ }^{12}$

The second level of openness is about the right and capability to enjoy the services generated by the resource. In the Free / Open Source terminology, when a resource is open in this sense, one can "use" the resource. We call OER that is open in this sense OER II. Whereas OER I makes it possible for a student to read a book or watch a video, OER II means that the student can use the book or video to pass a course or gain a certificate. ${ }^{13}$ The distinction between OER I and OER II is important, as it highlights the social and institutional dimension of openness. It is impossible see whether a resource is open or not simply by looking at the resource itself. OER II emerges as a combination of non-discriminatory access to the resource and a social arrangement that makes it possible to enjoy the services generated by the resource. For example, the MIT OpenCourseWare provides access to recorded lectures and digitized learning materials, but explicitly excludes any formal recognition of learning.

OER III emerges when the user has the right and capability to modify and add value to the resource. At this level, the user can remix, contextualize and recombine existing resources, and benefit from the improved resource. OER III makes possible, for example, just-in-time personalized learning.

Finally, OER IV emerges when the improved resource can be redistributed. This is the level where a new accumulative and expansionary dynamic of resource development emerges, as users can become producers who work on the received resource. In OER IV, the underlying growth dynamic becomes exponential and also a new collaborative dynamic of learning emerges. OER IV allows, for example, peer-based social learning that focuses on collective construction of knowledge and knowledge artifacts. This model underlies, for example, the Scratch software construction environment, developed at the MIT Media Lab (Monroy-Hernández and Resnick 2008). Scratch allows young kids to create and program games and develop and repurpose programs created by others, at the same time learning from the other users of the platform (Thomas and Brown 2011).

Many of the most visible OER initiatives have focused on providing free access to difficult to modify content, effectively remaining in OER I. OER II has been addressed by initiatives such as the Mozilla's Open Badge Infrastructure project ${ }^{14}$, which aims at creating an alternative recognition system for skills and educational achievements. The badge approach is also extensively used by the Khan Academy ${ }^{15}$, whereas Udacity ${ }^{16}$, for example, uses peer-based "karma points" and a four-level grading system, and has partnered with the electronic testing company Pearson VUE to provide controlled educational certificates. Coursera ${ }^{17}$, in turn, plans to provide secure testing and assessment services and to collaborate with its partner institutions to certify learning achievements. Also ed $\mathrm{X}^{18}$ is now planning to move towards OER II, as it plans to provides certificates of course

12 "Non-discriminatory access" has social, cultural, economic, technical, and individual dimensions that can best be understood in the capability-based approach, developed by Sen and Nussbaum (Sen 2000; Nussbaum 1995).

13 In some countries, copyright law may also force partial Openness II, for example, through fair use rules.

$14 \mathrm{http}: / /$ openbadges.org/

$15 \mathrm{http}: / /$ www.khanacademy.org/

$16 \mathrm{http}: / / \mathrm{www} \cdot$ udacity.com/

17 https://www.coursera.org/

18 https://www.edx.org/ 
completion. Coursera and edX, however, move with one foot solidly on each side of the fence, providing open access to learning with restricted, though perhaps low-cost, access to the benefits of education.

Whereas from an economic point of view OER I, II and III can be interpreted as public goods, they also show that OER and its impact can be understood only in a broader social and institutional context. The impact depends on the conditions under which the user can enjoy the services generated by the resource (Willems and Bossu 2012; Richter and McPherson 2012). These include technical capabilities such as network access and software that can effectively re-use and represent available content, but also base-level competences and social, economic, cultural and political conditions.

It it therefore necessary to locate specific open educational resources in a broader context where these resources are created and where they generate services. In the next section we briefly outline this broader context. An important element of this context is the prevailing intellectual property regime. Intellectual property rules, however, represent only one of the many social institutions that regulate how OER can generate benefits for its users, producers, and the society.

\section{OER in a user-producer context}

When OER consists of textual content, copyright rules to an important extent define the level of resource openness. OER I and II, for example, can be implemented using the Creative Commons "no derivatives" licenses, whereas OER IV can be enforced by "share alike" licensing. ${ }^{19}$ In general, copyright licenses, however, only partially define the openness of the focal resource. Resource openness can also be constrained by trademarks, database rights, patents, and, for example, proprietary file formats. Content use may be facilitated by fair-use rules and constrained by cultural norms and, for example, liability and national security laws. Many OER initiatives have so far focused on content that can be effectively regulated using copyrights, and the complexities of openness have remained relatively invisible. In particular, when OER is used to redistribute existing course content, which normally is adapted to local norms and laws, openness often appears to be a simple question about copyrights.

In general, the focal OER is not a monolithic object, and it may consist of components that have different degrees of openness. Conceptually, OER can perhaps best be viewed as boundary infrastructures that enable knowledge-based collaboration across diverse groups of actors (Star 2010; Bowker and Star 1999). This heterogeneity has implications both for the creation and use of the resource. For example, the possibilities to remix resources and create effective learning paths depend on the granularity, modularity, configurability, and scale of the focal OER. When OER moves beyond simple resource library models, for example, when OER platforms support dynamic configuration and personalized assessment, the technical dimension of openness becomes important, including interoperability, standards and interfaces.

From a pedagogical point of view, learning often requires guidance and scaffolding that helps the learner to proceed effectively and avoid sidetracks and cul-de-sacs. ${ }^{20}$ Such guidance can alternatively be viewed as a resource or as a constraint (Giddens 1984). A distinction between

19 http://creativecommons.org/

20 This was one of the insights underlying Vygotsky's zone of proximal development, which also provided the starting point for the community of practice models of learning (Lave and Wenger 1991; Brown and Duguid 1991). 
"open" and "closed" educational practices is therefore a complex issue both in theory and in practice. $^{21}$

In some cases it may be useful to explicitly restrict the openness of some components not only for the users but also for the producers. For example, the rapid growth of source code of the Linux open source operating system has been facilitated by strong social control of some key elements of the system. Although in open source projects the code is visible to all developers, not everyone is allowed to modify it. In the history of Linux, tight control of central elements has enabled rapid expansion of more peripheral elements, leading to very high rates of expansion in the overall functionality of the system (Tuomi 2001; 2002).

To simplify this complexity, in Figure 1 we depict three important domains that form the context of OER initiatives. First, the production of OER requires motivation, capability, and a resource base that is used in the production process. Second, the resource base that forms the context for production consists of tools, accumulated epistemic objects, as well as established communities with division of labor and rules that make collective effort possible. Third, the consumption or use of the produced OER generates knowledge and capabilities, and it can also produce further epistemic objects and tools. As consumption is in itself productive and the "consumers" of learning cannot readily be conceptualized as "sinks of knowledge," we use the term "prosumption" here. As the different models of learning require different degrees of heterogeneity, configurability and scale of the focal resource, we also single these out in the figure.

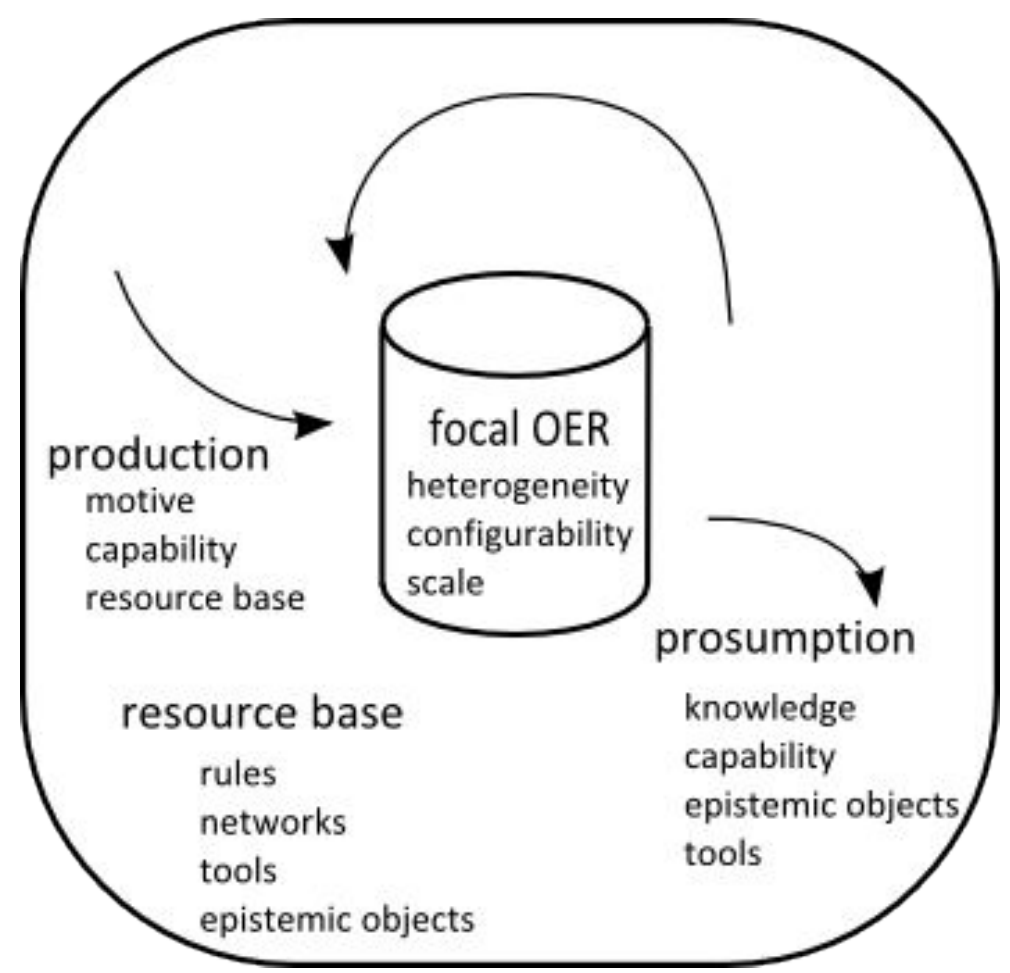

Figure 1: The production-prosumption context of focal OER.

21 Open and closed models of learning have been distinguished in the recently finalized EU-funded Open Educational Quality (OPAL) project (Ehlers 2011). Ehlers describes open educational practices as a movement from closed towards open models of learning, emphasizing the point that OER needs to be understood in a context of learning that extends beyond the focal resource. The importance of open practices has also been emphasized, for example, by Yin and Fan (2011). 
As Figure 1 highlights, openness of the focal resource makes sense only in a broader context that provides explicit and tacit rules that simultaneously constrain activity and make it possible. These rules encode substantial bodies of social knowledge and structure that gradually have evolved to address the needs of social life. To put it in very simple terms, these rules and structures define why learning and education make sense in a specific historical context. In the following section we therefore briefly outline this historical context, in an attempt to clarify why and whether OER could make sense in the educational systems of the future.

\section{OER and learning in the Knowledge Society}

Each historical era creates a system of education that addresses its needs. The diffusion and impact of OER partly depends on whether it makes the current educational system more productive and effective. OER, however, can also be a transformative force. It can help current educational institutions to adapt to emerging new social requirements, and it can provide a breeding ground for qualitatively new systems of learning that emerge outside current institutional frameworks. The impact and future of OER therefore depends partly on how its evolutionary dynamic and its propensities and possibilities align with the requirements of current educational systems, and partly on how it allows these systems to respond to requirements of the post-industrial knowledge society.

In the pre-industrial European society, the family and the immediate community were the focal points in education, and children were able to perceive and participate in almost all productive activities. As Dewey noted:

"The supply of flour, of lumber, of foods, of building materials, of household furniture, even of metal ware, of nails, hinges, hammers, etc., was in the immediate neighborhood, in shops which were constantly open to inspection and often centers of neighborhood congregation. The entire industrial process stood revealed, from the production on the farm of raw materials, till the finished article was actually put to use." (Dewey 1915, 23)

In contrast to this transparent system of production, the industrial system created a complex division of labor and specialization, where the household lost its capability to provide vocational education and where specialized locations of learning had to be set up. The rapidly accelerating urbanization and migration, driven by the increasing role of factories as centers of work and earning, also generated unprecedented social diversity. In this process, the home, the workplace, community life, and the church lost many of their earlier functions in the educational system, and the school became a central institution in education.

The industrial mode of production therefore did not only lead to a problem of transferring productive skills; it also generated important new requirements for education. First, the effective combination of human workers with machinery requires clocks, punctuality and tight coordination. Second, the splicing of productive activities into specialized tasks requires hierarchical control, coordination and obedience. Third, factory workers have to accept the fact that the motives and meaning of productive tasks are increasingly unknown. Fourth - specifically after the introduction of scientific management methods in industry - the workers had to be able to read and write documents that defined work processes and standards. ${ }^{22}$

22 This section draws on Tuomi, I., and R. Miller (2011) Education and Learning After the Industrial Age. Discussion Paper, The Finnish Confederation of Industries. 
The gradually increasing wealth, health, and leisure time, combined with rapidly increasing rates of literacy, also enabled people to search for new sources of meaning. As Inglis $(1918,373)$ noted in his extensive study on the aims and functions of education: "Factory labor has tended to reduce the economic activity of the worker to a level of deadening monotony where either development or enjoyment is reduced to lowest terms." Formal education was thus also needed to compensate this decline in opportunities for personal development, as well as to provide the foundation for effective coordination, management, and collaboration of increasingly complex and diversified societies

With some simplification, we can thus say that the modern educational system responds to four major societal needs.

First, from a systemic point of view, education simplifies social complexity and increases its predictability (Luhmann 1995). Education has an important role in reproducing and creating social groups and social stratification. It generates social categories that collate large numbers of individuals in groups that can be represented by statistical numbers with prototypical characteristics, making planning and large-scale administration and thus the modern state possible (Webster 1995, chap. 4; Giddens 1985).

Second, as noted by Dewey and others, the industrial system requires specialized education of productive skills and also more general-purpose competences such as literacy and numeracy that make efficient production possible. Literacy and numeracy, in particular, have been the key competences required by efficient coordination and control of productive processes in the industrial age. In advanced economies, the expansion of production and consumption has also been supported by the fact that schools have allowed parents to go to work outside the home.

Third, education also generates attitudes and knowledge that, beyond their effect of production, underlie political and cultural systems, and provide the foundation for the society. This is the "cultural transfer" and "enculturation" function of education. Education is required to make full social participation possible.

Fourth, modern education also aims at personal development. The importance of personal development and "the complete fulfillment of man, in all the richness of his personality" (as stated in the Learning To Be report by UNESCO in 1972), has been emphasized since the romantic image of individual became popular in the early $19^{\text {th }}$ century (Taylor 1989).

The four functions of social simplification, productivity, cultural transfer, and personal development are rather generic, and could be compared with the more learner-focused four pillars of learning defined by UNESCO (1996, chap. 2). ${ }^{23}$ The way in which these functions are implemented, however, varies in different social, historical, cultural and techno-economic contexts. Education reduces social complexity; it increases the efficiency of productive processes; it generates socially shared systems of meaning that enable collective action and social development; and it facilitates individual development and realization of human potential. The ongoing transformation from the industrial society towards the knowledge society profoundly changes the conditions for implementing these social functions, and OER potentially plays an important role here. It is in this context where the potential impact of OER is most clearly visible.

Table 1 compares the different ways to implement the four societal functions of education in the industrial and knowledge societies. In the present paper, we do not detail these differences. Instead,

23 The four pillars of UNESCO distinguish "learning to know," "learning to do," learning to live together," and "learning to be." 
they are used to highlight the societal level of analysis that puts OER in a historical context. Here we define social functions and "demand" at a level that is independent of their technical implementation, thus avoiding the old dichotomy of technology push vs. demand pull. The question about "social demand" for OER, then simplifies to a question whether OER provides some clear benefits in implementing the technology-independent social functions of education. To address this question, we need to understand whether the wide use of OER could make learning more productive, and whether it could make the institutions of education better adapted to the requirements of the knowledge society.

\begin{tabular}{|l|l|l|}
\hline \multicolumn{1}{|c|}{ Social function } & \multicolumn{1}{|c|}{ Industrial Society } & \multicolumn{1}{c|}{ Knowledge Society } \\
\hline Stratification / simplification & Hierarchical & $\begin{array}{l}\text { Networked / heterarchical / } \\
\text { informational }\end{array}$ \\
\hline Productivity & $\begin{array}{l}\text { Specialized and mechanized } \\
\text { work }\end{array}$ & $\begin{array}{l}\text { Continuous learning, meaning } \\
\text { processing, and knowledge } \\
\text { creation }\end{array}$ \\
\hline Enculturation & Unified national cultures & $\begin{array}{l}\text { Cultural diversity, transient } \\
\text { communities and networks }\end{array}$ \\
\hline Personal development & $\begin{array}{l}\text { Trans-generational progress, } \\
\text { realization of latent individual } \\
\text { potential through vocation and } \\
\text { social role }\end{array}$ & $\begin{array}{l}\text { Realization of human } \\
\text { capabilities, increasing } \\
\text { capability to realize value and } \\
\text { make choices }\end{array}$ \\
\hline
\end{tabular}

Table 1: Different models of implementation of the four social functions of education.

\section{Learning with OER}

Given the different types of OER and the context in which they are produced and prosumed, we may now try and clarify the impact of OER on learning and education. As Kools and Istance (in this issue) emphasize, the availability of a new technology does not lead to any deterministic outcomes or impact, and emerging technical possibilities can be used in many different ways. It is possible to implement all existing pedagogic models using OER. At the same time, OER has specific propensities and affordances that match better with some models of learning than others.

To consolidate the vast area of often contested and conflicting views of what learning is and how it happens, we focus on two analytical dimensions: the unit of analysis and the degree of explicit learning dynamics.

In the dimension that distinguishes different units of analysis, we separate individualistic and distributed models. In degree of dynamics, we distinguish between models that view learning as transfer of knowledge to a repository and models that are based on more elaborated process models of learning. At the individualistic end we locate those behavioristic, cognitivist-representational, associationistic, and neural learning models where the unit of analysis is the individual learner. At the distributed end we include socially and socio-materially distributed models. Using these two analytical dimensions, we can map the previously introduced four types of OER in Figure 2. 


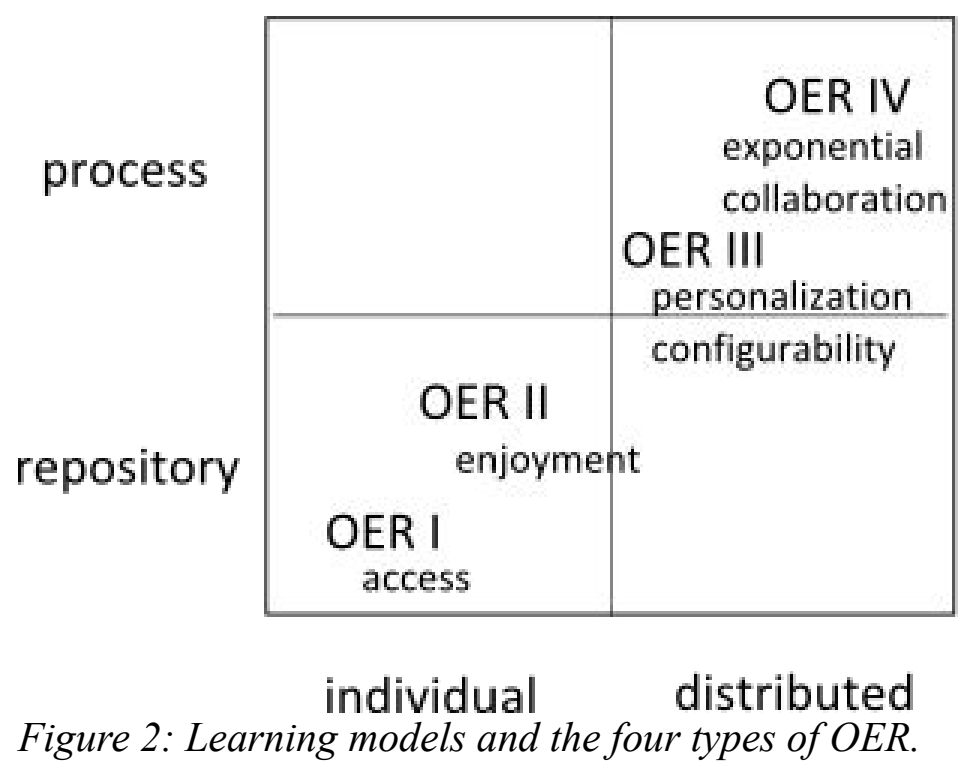

The traditional knowledge transfer model of instruction would in this picture be located at the individualistic and repository end. This is the "storehouse of ideas" model where the human memory provides a repository "where the mind can lay up those ideas which, at another time, it might have use of" (Locke 1979, 150). ${ }^{24}$ The distributed models of learning would, in turn, include a large interrelated cluster of cultural-historical, activity-theoretic, socio-cultural, situated, ecological, distributed, and extended cognition models. The far end of the distributed side would also include community-oriented constructionism, design learning, and the trialogical model (Kafai and Resnick 1996; Paavola and Hakkarainen 2009), as well as the knowledge building model of Scardamalia and Bereiter (2006; Bereiter 2002), where the unit of learning at least partially moves to the world of collectively shared knowledge objects. ${ }^{25}$ Distributed models of learning, by their nature, tend to incorporate process aspects. These, however, become pronounced in explicitly cyclical models (e.g., Kolb 1984; Nonaka 1994; Engeström et al. 1996), as well as in reflective learning (Schön 1987) and action learning (Boshyk and Dilworth 2010), but also, for example, in Schank's (2011) recent reinterpretation of the cognitivist model.

There are many learning models, and often they are complementary, overlapping, and contradictory. The concept of "resource" already implicitly assumes productive use, and OER therefore easily aligns with constructivist and constructionalist models. When OER provides digitized network accessible resources it also aligns well with distributed models.

An alternative view on these analytical dimensions is provided by mapping open licenses to the picture. Figure 3 shows that there is actually a close correspondence between licensing conditions and specific learning models. Whereas, for example, the Creative Commons "attribution" license (CC BY) can support the entire spectrum of learning models, the "no derivatives" license (CC ND) effectively inhibits distributed and process-oriented learning models. The Creative Commons "share-alike" license (CC SA), in turn, becomes salient only when the underlying learning model is

24 More modern versions of repository oriented models would include the script, schema, and cognitive frame models inspired by Bartlett, Piaget and AI, but also many recent models influenced by cognitive neurosciences.

25 An example of a highly distributed model would also be the connectivist model proposed by Stephen Downes and George Siemens. In the connectivist model, learning consists of the formation of connections between nodes of information, and "learning is the network" (Kop and Hill 2008). Assuming the existence of mechanisms that drive changes in the network, connectivism could perhaps be understood as a self-organizing network model of collective cognition, extended to an abstract world of information. Whether this would lead to a $19^{\text {th }}$ century associationistic views on learning or new insights remains unclear until the basic concepts of this model are further elaborated. 
socially distributed and the learning process unfolds in time. By enforcing re-usability and further developments, the CC SA license thus aligns well with collaborative and constructionalist models of learning.

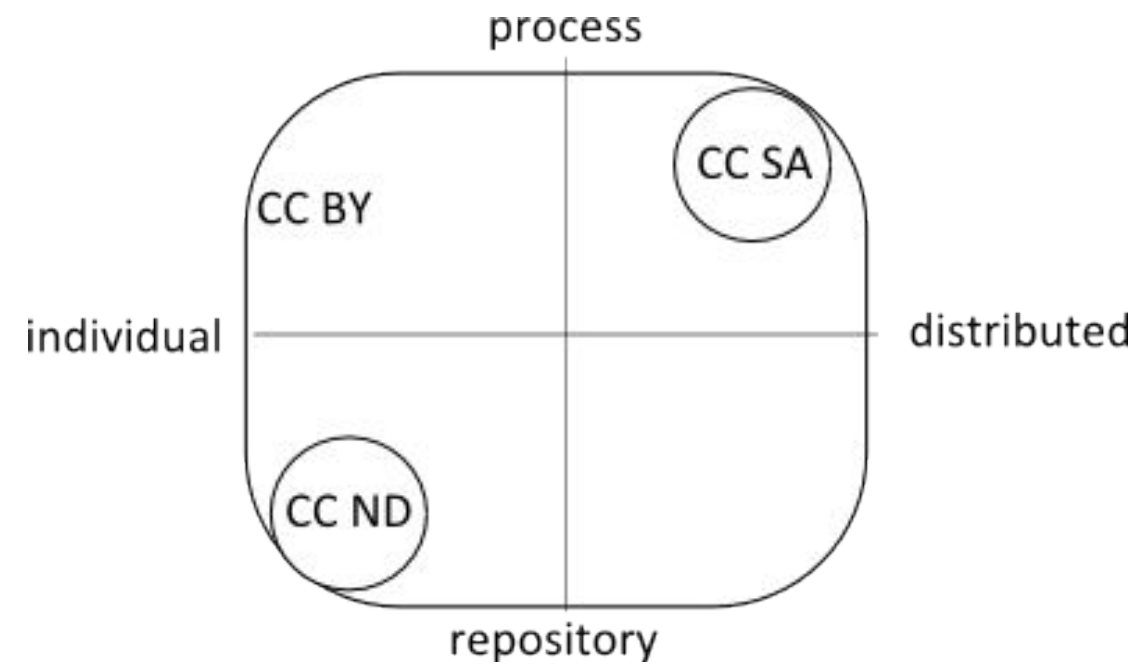

Figure 3: Creative Commons licenses and their respective learning models.

The above analysis provides a highly simplified picture of the key affordances of the different types of OER and their relations with different models of learning. It is possible to combine process-based and repository models, for example, by adopting a learning model that incorporates learning processes that occur in different time-scales. The Vygotskian model, in fact, is based on such a layered model of development (Luria and Vygotsky 1992). It is, however, clear that different types of OER resonate with different types of learning models. We may therefore ask whether distributed and process-oriented models of learning would be more effective than individualistic repositoryoriented models, and whether OER could release hidden learning potential and improve learning productivity. If learning is today difficult because of material, social and economic constraints, would OER make a difference? If education implements its societal functions in ways that try to optimally address the concrete requirements of the industrial age, would OER facilitate the renewal of existing educational institutions?

\section{OER and the transformation of education}

Using the four social functions of education listed above in Table 1, and the outline of the propensities and affordances of OER presented in the previous section, we can now ask whether OER can be used to move education from the industrial era towards the knowledge society.

It is clear that the wide use of networked information and communication technologies, as such, has already created new means for social simplification and stratification. Internet search engines and social filtering and recommendation systems are able to dynamically cluster and profile vast numbers of users at scales unimaginable just two decades ago. Education, at least to some extent, is being replaced by "big data" and statistical methods. Education therefore plays a rapidly decreasing role in social simplification and stratification. In the networked, heterarchical and dynamic knowledge society, the simplification of social complexity cannot easily rely on slowly changing established hierarchies and fixed social roles. 
The cultural transfer function, in turn, is increasingly implemented in culturally diverse contexts, where identities and communities are dynamic and transient. Education thus moves from transgenerational "vertical" socialization towards peer-based "horizontal" social learning. This is clearly compatible with the basic characteristics of OER IV. On the other hand, OER also enables increasing contextualization and localization of the production of knowledge and learning, allowing different communities to develop local systems of enculturation. OER can therefore also facilitate the emergence of geographically, ethnically, and culturally specialized education and, for example, the expansion of value-centric education and anti-schooling movements where identities are constructed with strong community-specific values.

Through its capacity to provide wide access to customizable and configurable learning resources, OER III will clearly have a major impact on possibilities for personal development. As individual identities are essentially social constructs, OER IV enables learning that is strongly linked to identity formation and the expansion of personal expression. OER thus facilitates just-in-time personalized and self-directed learning, and provides new possibilities for identity construction and expression in a wide-variety of globally distributed communities. Due to its capability to make learning socially visible and connect peripheral stakeholders to learning processes, it also facilitates learning models that connect learning to social change. OER, therefore, can support the expansion of action learning and critical pedagogies, and for example reduce the "isolation" and "encapsulation" of school learning (Engeström 1996).

The potential impact of OER in the productive dimension is somewhat more complicated. In the industrial age, specialized skills were critical for productivity, and these skills were typically complementary to specific tools used in production. In a given material and technical environment, as it is found on the factory floor, for example, it is possible to define relatively static catalogs of skills and provide training related to them. In this sense, the concept of skill is an artifact of the industrial model of production.

In knowledge-intensive production, many of the traditionally well-defined skills become outdated. The context of work is not a static production line on a factory floor; instead, it is a dynamic and continuously changing landscape of learning and knowing. Much of the traditional educational content that focuses on productive skills thus becomes irrelevant as we move towards the knowledge society. Wide access to outdated content does not necessarily lead to more productive societies.

The impact of OER on society's production potential, thus, depends on how well the pedagogic models used in OER support the development of those capabilities that are productive in the knowledge society. At present, this is still very much an open research question. Abstract and generic " $21^{\text {st }}$ Century skills," such as innovation and problem-solving capabilities, communication skills, and "learning skills" may require new educational practices and cultures. A straightforward promotion of OER may diffuse outdated pedagogic ideas and content, thus reducing the productive potential instead of augmenting it.

A major promise of OER is that the creation and refinement of both learning content and the underlying pedagogical approaches can benefit from the distributed co-creation model enabled by open licenses. In principle, a rich developer base facilitates the creation of resources. In practice, the benefits may, however, depend on the type of content and resource developed. This is perhaps best illustrated in a Hayekian model of knowledge creation. 
For Hayek (1945), a knowledge-based economy is characterized by the fact that no single individual is able to know as much as all social actors know together. According to Hayek, important stocks of socially relevant knowledge are tacit. In addition to these tacit bodies of knowledge, people rely on their own personal, local, contextual and idiosyncratic knowledge when they make consumption and production decisions. Hayek's argument was that because of this distributed and tacit nature of socially and economically relevant knowledge, centrally planned policies and explicit organizing almost always perform worse than a free market of ideas and action. $^{26}$

Open source and open content developer communities have characteristics that resemble Hayek's free markets of knowing. In principle, when each developer is able to contribute her unique knowledge and competences to a collaborative project, the outcome can exceed the possibilities of any single actor or any centrally planned effort. We may call this the "Hayekian benefit" of OER.

The Hayekian benefit has been visible in open source software projects. Software development, however, is special because the developed code also provides unambiguous methods for verifying efficiency and knowledge claims (Tuomi 2002). The code can be executed, and its performance can be objectively measured. When such objective criteria do not exist, as is the case, for example, when multiple persons develop content in parallel for WikiPedia, joint effort does not necessarily converge towards a stable outcome. In a world of many conflicting truths, the benefits of distributed collaboration can be limited.

In some cases, the "objectiveness" of knowledge can be verified empirically. In others, the benefits of idiosyncratic personal knowledge may be limited because knowledge is inherently social. For example, natural sciences and mathematics rely on theoretical conceptual systems that embody trans-generational and interpersonal knowledge. As Vygotsky (1986) pointed out, there are essentially two different types of concepts. Some concepts are "spontaneous concepts" that a child learns in interaction with the material and social environment. According to Vygotsky, advanced forms of thought emerge when these spontaneous concepts become replaced by "theoretical" concepts. These systems of "theoretical" concepts are socially and culturally shared and generated, and they are acquired gradually in social interaction as the human mind develops its advanced mental capabilities.

For these types of knowledge systems, the Hayekian benefits can reduce to a simple mechanistic division of labor. Personal knowledge and diversified views about what is the result of multiplying two numbers may not exist. When coordination costs are low and joint effort is easy, crowds may work effectively for a joint objective. When local interpretation and personal knowledge have limited relevance, and knowledge is inherently social and explicit, central planning and organizing may be more effective. In such a situation, the OER model, as a distributed peer-production model, may have little benefit and the costs of collaboration may easily become dominant.

From a learner-centric point of view, OER facilitates distributed learning processes where resources can be dynamically adapted according to specific learner requirements and where learners can efficiently borrow cognitive capabilities from their social and technical environment. Learning can potentially be very effective and productive in such an environment. Personalized and networked learning environments may thus look attractive and promise great improvements in learning

26 Hayek, who viewed the economy as a collective learning process, developed this argument in a large number of writings, nowadays frequently and rather liberally quoted by anti-government and libertarian movements. Hayek's views on the nature of knowledge were influenced by his discussions with Michael Polanyi, who is today best known for his concept of tacit knowledge (Mirowski 1998). 
productivity. Such personalized models, however, require extensive systems of learning diagnostics and analytics that may be difficult to implement in open environments. In practice, they require detailed information about the current knowledge and capabilities of individuals. This creates radically new domains of social transparency. Many current OER initiatives, for example, aim at providing detailed data on the progress of a student to the teachers and parents. A limited but an interesting example of such new regime of social visibility is also included in the list the possible monetization approaches proposed by Coursera to its stakeholders and venture capitalists (Young 2012). In this business scenario, Coursera would make money by opening the student records to potential future employers, so that the students can reveal their learning achievements and the employer can select the best performing students.

At a more societal level, and perhaps more fundamentally, it is at present unclear to what extent the traditional productive function of education remains relevant in the knowledge society. Learning clearly will have a major impact on how and what the society and its members produce. As was pointed out above, the current educational system, however, responds to the historical need to generate generic competences and specialized skills that are needed in the industrial system of production. The ways in which these generic competences and specialized skills are articulated today are to a large extent based on a model of production where humans and machines are coupled together in an industrial machine. The essence of the industrial system is in its capability to mix human and mechanical actors to produce higher volumes of output. As has been pointed out by Zysman (2006), the emerging ICT-enabled networked production models are not necessarily compatible with this industrial model of production. In the current global and networked world, where networks of production are dynamically configured on demand with a click of mouse and a tap of a finger, there is no time or space for human intervention in the actual production process. This means that all those tasks that are rule-based or can be routinized need to be implemented using algorithms if they are to be connected to the global network of production. This is the "algorithmic revolution" highlighted by Zysman. In practice, this could mean that almost all those specialized tasks for which the industrial age educational system tried to produce skills will become obsolete as the knowledge society transformation proceeds. There may be therefore little benefit from the rapid expansion of access provided by OER if it supports vocational learning, but also learning in areas commonly associated with white-collar knowledge work.

\section{Conclusion}

The very rapid expansion of the number of OER initiatives and the millions of learners they attract can easily be interpreted as an indicator of a forthcoming revolution in education and learning. This paper has developed conceptual background that can help in studying this potential revolution in its broader social, economic, and historical context. Technology never determines social outcomes, and the ways in which OER will be used depend to a large extent on its capacity to make learning effective and to address existing and emerging social needs for education.

This paper started by defining four different types of OER. Methodologically robust studies on OER require different ways to frame these different types of OER. We outlined one way to put OER in the context of production and prosumption that highlighted the importance of the social and institutional foundations that make OER meaningful. To understand this social context, we then in a very compressed way described the historical origins of current educational systems as a response to social needs that emerged in the industrial revolution, highlighting the different ways in which solutions for these social needs are implemented in the industrial age and in the knowledge society. The underlying argument was that the current institutions of education are solutions to historical 
needs, articulated under the constraints of the past. When the constraints, needs, and the underlying conceptual frameworks change, also educational institutions respond to these changes. Against this background we tried to see whether and how the different types of OER could be part of the transformation of education and learning.

The approach used was multidisciplinary. It may appear theoretical from a point of view of an educator or a policymaker who thinks that the issue is about free access to textbooks, wide access to high-quality teaching, and the wonders of social media. We supported the argument using literature that ranged from economics to innovation and technology studies, sociology, learning theories and the history of education. It is, of course, only possible to scratch the surface here. The point, however, is that education is a deeply social and historical issue and that, as Olson and Bruner (1996) pointed out, the institution of education is inextricably linked with our ideas about what knowledge is and how learning occurs. To understand and study the impact of OER in education and learning, and to develop useful policies, we have to put OER in this broader theoretical context. OER is not just textbooks in the cyberspace. If it is anything, it is part of a highly complex and continuously evolving system that plays an important role in making effective human collaboration and individual creativity possible.

Beyond descriptive reviews of this rapidly moving phenomenon, a study on OER is therefore inherently a study on social and educational transformation. OER reorganizes the boundaries of social transparency and it enables new forms of collaboration and production. In so doing, it provides a rich field of research on both the current and the emerging forms of education and learning. The OER movement is itself driven by rapidly changing information and communication technologies, which at present are profoundly transforming social interactions, systems of production, and the possibilities for individual development and expression. The emerging knowledge society will have new requirements for education and new models for learning. In this transformation, OER will most probably be a central element.

\section{References}

Atkins, D.E., J.S. Brown, and A.L. Hammond. 2007. A review of the Open Educational Resources (OER) movement: Achievements, challenges, and new opportunities. Menlo Park: The William and Flora Hewlett Foundation.

Benkler, Y. 2006. The wealth of networks: How social production transforms markets and freedom. New Haven, CT: Yale University Press.

Bereiter, C. 2002. Education and mind in the knowledge age. Mahwah, NJ: Lawrence Erlbaum Associates.

Boshyk, Yury, and Robert Dilworth, eds. 2010. Action learning: History and evolution. Palgrave Macmillan.

Bowker, G., and S.L. Star. 1999. Sorting things out: Classification and its consequences. Cambridge, MA: The MIT Press.

Brown, J.S., and P. Duguid. 1991. Organizational learning and communities of practice: toward a unified view of working, learning, and innovation. Organization Science 2 (1): 40-57.

Buchanan, James M., and Yong J. Yoon, eds. 1994. The return to increasing returns. University of Michigan Press.

Butcher, N. 2011. A basic guide to open educational resources (OER). Vancouver: Commonwealth of Learning.

Daly, H.E., and J.B. Cobb. 1989. For the common good: Redirecting the economy toward community, the environment, and a sustainable future. Boston: Beacon Press. 
De Langen, F. 2011. There is no business model for open educational resources: A business model approach. Open Learning: The Journal of Open and Distance Learning 26 (3): 209-22.

Dewey, J. 1915. The school and society. University of Chicago Press.

EC. 2012. Rethinking education: Investing in skills for better socio-economic outcomes. Strasbourg: European Commission.

Ehlers, U.-D. 2011. From open educational resources to open educational practices. ELearning Papers (23): 1-8.

Engeström, Y. 1996. Non scolae sed vitae discimus: Toward overcoming the encapsulation of school learning. In An Introduction to Vygotsky, ed by. H. Daniels, 151-70. London: Routledge.

Engeström, Y., J. Virkkunen, M. Helle, J. Pihlaja, and R. Poikela. 1996. The change laboratory as a tool for transforming work. Lifelong Learning in Europe 1 (2): 10-7.

Giddens, A. 1984. The constitution of society: Outline of the theory of structure. Berkeley, CA: University of California Press. 1985. The nation state and violence. Cambridge: Polity.

Gourley, B., and A. Lane. 2009. Re-invigorating openness at The Open University: The role of Open Educational Resources. Open Learning: The Journal of Open and Distance Learning 24 (1): $57-65$.

Grossman, L. 1998. New Free License to Cover Content Online. TIME Digital - September 18, 1998.

Hardin, G. 1968. The Tragedy of the Commons. Science 162 (3859) (December 13): 1243-8.

Hayek, F.A. 1945. The use of knowledge in society. American Economic Review 35 (4): 519-30.

Hess, C., and E. Ostrom. 2003. Ideas, artifacts, and facilities: information as a common-pool resource. Law and Contemporary Problems 66 (1/2): 111-45.

Hylén, J., D. Damme, F. Mulder, and S. D'Antoni. 2012. Open educational resources: analysis of responses to the OECD Country Questionnaire. OECD Education Working Papers. OECD.

Inglis, A.J. 1918. Principles of secondary education. Boston; New York: Houghton Mifflin Company.

Kafai, Yasmin B., and Mitchel Resnick, eds. 1996. Constructionism in practice: Designing, thinking, and learning in a digital world. Routledge.

Kolb, D. 1984. Experiental learning: experience as the source of learning and development. Englewood Cliffs, NJ: Prentice Hall.

Kop, R., and A. Hill. 2008. Connectivism: Learning theory of the future or vestige of the past? The International Review of Research in Open and Distance Learning 9 (3) (July 18). http://www.irrodl.org/index.php/irrodl/article/view/523.

Laakso, M., P. Welling, H. Bukvova, L. Nyman, B.-C. Björk, and T. Hedlund. 2011. The development of open access journal publishing from 1993 to 2009. PLoS ONE 6 (6) (June 13). http://www.ncbi.nlm.nih.gov/pmc/articles/PMC3113847/.

Lave, J., and E. Wenger. 1991. Situated learning: Legitimate peripheral participation. Cambridge: Cambridge University Press.

Locke, J. 1979. An essay concerning human understanding. Ed by. Peter H. Nidditch. Oxford University Press.

Luhmann, N. 1995. Social systems. Stanford, CA: Stanford University Press.

Luria, A.R., and L. Vygotsky. 1992. Ape, primitive man, and child: Essays in the history of behavior. Hemel Hempstead: Harvester Wheatsheaf.

McAndrew, P. 2010. Defining openness: updating the concept of "open" for a connected world. Journal of Interactive Media in Education 2010: 1-13.

Mirowski, P. 1998. Economics, science, and knowledge: Polanyi vs. Hayek. Tradition \& Discovery, The Polanyi Society Periodical XXV (1): 29-42. 
Monroy-Hernández, A., and M. Resnick. 2008. Empowering kids to create and share programmable media. Interactions XV (2): 50-3.

Nonaka, I. 1994. A dynamic theory of organizational knowledge creation. Organization Science 5 (1): 14-37.

Nussbaum, M.C. 1995. Human capabilities, female human beings. In Women, Culture, and Development, ed by. J. Glover, 61-104. Oxford: Clarendon Press.

O’Mahony, S. 2003. Guarding the commons: how community managed software projects protect their work. Research Policy 32 (7): 1179-98.

OECD. 2007. Giving knowledge for free: The emergence of open educational resources. Paris: OECD.

Okada, Alexandra, Teresa Connolly, and Peter J. Scott, eds. 2012. Collaborative Learning 2.0: Open Educational Resources. Hershey, PA: IGI Global.

Olson, D.R., and J.S. Bruner. 1996. Folk psychology and fold pedagogy. In Handbook of education and human development: New models of learning, teaching and schooling, ed by. D.O. Torrance and N. Torrance, 485-513. Cambridge, MA: Basil Blackwell.

Oram, A. 2001. Peer-to-peer: Harnessing the power of disruptive technologies. Sebastopol, CA: O'Reilly \& Associates.

Paavola, S., and K. Hakkarainen. 2009. From meaning making to joint construction of knowledge practices and artefacts - A trialogical approach to CSCL. In Computer Supported Collaborative Learning Practices: CSCL2009 Conference Proceedings, ed by. C. O’Malley, F. Suthers, P. Reimann, and A. Dimitracopoulou, 89-92. Rhodes: International Society of the Learning Sciences.

Plotkin, H. 2002. All Hail Creative Commons: Stanford professor and author Lawrence Lessig plans a legal insurrection. SFGate. http://www.sfgate.com/news/article/All-Hail-CreativeCommons-Stanford-professor-2874018.php.

Raymond, E.S. 1999. The cathedral and the bazaar: Musings on Linux and open source by an accidental revolutionary. Sebastopol, CA: O'Reilly \& Associates, Inc.

Richter, T., and M. McPherson. 2012. Open educational resources: Education for the world? Distance Education 33 (2): 201-19.

Sample, I. 2012. Free access to British scientific research within two years. The Guardian, July 16.

Scardamalia, M., and C. Bereiter. 2006. Knowledge building: Theory, pedagogy, and technology. In Cambridge Handbook of the Learning Sciences, 97-118. New York: Cambridge University Press.

Schaffert, S. 2010. Strategic integration of open educational resources in higher education. In Changing Cultures in Higher Education, ed by. Ulf-Daniel Ehlers and Dirk Schneckenberg, 119-31. Springer Berlin Heidelberg.

Schank, R.C. 2011. Teaching minds: How cognitive science can save our schools. Teachers College Press.

Schön, D.A. 1987. Educating the reflective practitioner: Toward a new design for teaching and learning in the professions. San Francisco, CA: Jossey-Bass Publishers.

Sen, A. 2000. Development as Freedom. New York: Anchor Books.

Star, S.L. 2010. This is not a boundary object: Reflections on the origin of a concept. Science, Technology \& Human Values 35 (5) (September 1): 601-17.

Suber, P. 2012. Open access. The MIT Press.

Taylor, C. 1989. Sources of the self: The making of the modern identity. Cambridge: Cambridge University Press.

Thomas, D., and J.S. Brown. 2011. A new culture of learning: Cultivating the imagination for a world of constant change. CreateSpace Independent Publishing Platform.

Thurow, L.C. 1975. Education and economic inequality. In The "Inequality" Controversy: Schooling and Distributive Justice, 170-84. New York: Basic Books. 
Tuomi, I. 2001. Internet, innovation, and open source: Actors in the network. First Monday 6 (1). http://firstmonday.org/htbin/cgiwrap/bin/ojs/index.php/fm/article/viewArticle/824/733. . 2002. Networks of innovation: Change and meaning in the age of the Internet. Oxford: Oxford University Press.

. 2005. The future of open source. In How Open is the Future?, ed by. M. Wynants and J. Cornelis, 429-59. Brussels: VUB Brussels University Press.

2006. Open educational resources: What are they and why do they matter. Report prepared for the OECD, Centre for Educational Research and Innovation.

http://www.meaningprocessing.com/personalPages/tuomi/articles/OpenEducationalResource s_OECDreport.pdf.

UNESCO. 1996. Learning: The Treasure Within. Paris: UNESCO.

. 2002. Forum on the Impact of Open Courseware for Higher Education in Developing Countries: Final report. Paris. http://unesdoc.unesco.org/images/0012/001285/128515e.pdf. . 2012. 2012 Paris OER Declaration. Paris.

http://www.unesco.org/new/fileadmin/MULTIMEDIA/HQ/CI/CI/pdf/Events/Paris\%20OER $\% 20$ Declaration_01.pdf.

Weber, S. 2004. The success of open source. Boston, MA: Harvard University Press.

Webster, F. 1995. Theories of the information society. London: Routledge.

Willems, J., and C. Bossu. 2012. Equity considerations for open educational resources in the glocalization of education. Distance Education 33 (2): 185-99.

Von Hippel, E., and G. von Krogh. 2003. The private-collective innovation model in open source software development: Issues for organization science. Organization Science 14 (2): 20923.

Vygotsky, L. 1986. Thought and language. Cambridge, MA: The MIT Press.

Yin, Y., and L. Fan. 2011. Trends of open educational resources in higher education. In Hybrid Learning, ed by. Reggie Kwan, Joseph Fong, Lam-for Kwok, and Jeanne Lam, 6837:14656. Lecture Notes in Computer Science. Springer Berlin / Heidelberg.

Young, J.R. 2012. Inside the Coursera Contract: How an Upstart Company Might Profit From Free Courses. The Chronicle of Higher Education, July 19, sec. College 2.0. http://chronicle.com/article/How-an-Upstart-Company-Might/133065/.

Zysman, J. 2006. The algorithmic revolution---the fourth service transformation. Communications of the ACM 49 (7): 48. 